\title{
Zero-gravity wardrobes: The behaviour of costume in weightless environments
}

Barbara Brownie

University of Hertfordshire

\section{Introduction: Creative Engagement with Weightlessness}

We are witnessing a convergence of science-fiction and science fact. At the dawn of the commercial space age, when it is possible for private companies or individuals to purchase a trip to space, it is increasingly possible to depict authentic extra-terrestrial environments, and for audiences to identify authenticity in those depictions. Andrew M. Thorpe (2009: 27) lists potential commercial space station clients as including not only researchers conducting pure science experiments, but also creative organizations such as television and film production companies, with the aim of producing music videos, educational and reality shows, and science-fiction movies. The potential for the creative industries' involvement in space activities presents orbiting space stations as interdisciplinary venues, where innovation can be technological, cultural, or aesthetic. One particular attraction of space as a site for fiction, and a location for filming, is weightlessness (microgravity, or $0 \mathrm{G}$ ). While these other industries have committed to taking advantage of the burgeoning commercial space industry, the creative industries have not yet fully established a relationship with the weightless environment. Weightlessness offers an enticing extraterrestrial experience for potential space tourists and creative practitioners alike (Peeters 2010: 1627).

Science fiction film and television typically employs digital animation to simulate the effects of weightlessness on bodies and the clothes that they wear (as in Passengers, Tyldum, 2016). These computer generated elements are often combined with practical effects, including rigs and harnesses to elevate actors' bodies and create the impression that they are not weighted to a surface (as in Ender's Game, Hood, 2013). Occasionally these practical effects are used without digital intervention (as in Mission To Mars, De Palma, 2000; Interstellar, Nolan, 2014). The results of each of these methods range from the sublime to the ridiculous. ${ }^{1} \mathrm{~A}$ weightlessness-like effect has applications beyond science-fiction and depictions of spacefarers. There is a haunting and remarkable near-stillness in the forms adopted by weightless artefacts that differentiates their behavior from those in Earth gravity (1G), and these effects are effective at expressing otherworldliness or surrealism in dream sequences or other scenes of fantasy. Films including It (Muschietti, 2017) and Inception (Nolan, 2010) 
have explored the potential for weightlessness-like effects without reference to spaceflight, for the purpose of visual spectacle, or to create a sense of the ethereal or otherworldly. Though these examples don't explicitly depict spaceflight, they employ similar effects to those caused by weightlessness in order to produce ethereal and often beautifully fluid shapes and textures, or to convey a sense of physical disorientation.

The availability of high-resolution footage from the International Space Station (ISS) makes audiences increasingly familiar with the real-life effects of weightlessness, and therefore more able to recognise the awkward uncanniness and inauthenticity of digital or practical simulations of weightlessness. As the commercial space age is in its infancy, there are not yet opportunities to commercially shoot films on board spacecraft. There are, however, other locations in which the effects of weightlessness can be authentically captured on film. Reduced-gravity aircraft fly in parabolic arcs, leading to short period of freefall, during which objects and passengers inside the craft experience the effects of weightlessness. Operators including the Zero Gravity Corporation and Air Zero G/Novespace offer commercial passengers and researchers opportunities to capture the effects of weightlessness over short periods of 20-30 seconds, as well as a variety of other gravitational conditions including hypergravity. These environments provide potential locations for the authentic recording of the effects of weightlessness.

The availability and affordability of reduced-gravity flights, combined with an interest in space as a location for film and television fiction, creates a need for costume designers to be aware of the effects of weightlessness of clothing, and a need for costumes to be designed with those affects in mind. Reduced gravity aircraft have been the location for a variety of performances and other creative endeavours, all of which have required thoughtfully selected costumes, including a theatrical performance by Cosmokinetic Cabinet Noordung in 1999, Gravitation Zero - Noordung Biomechanics (Grzinic 2003: 82), dance performed and choreographed by Kitsou Dubois in 2000 as part of a number of engagements with weightlessness that were funded by Arts Catalyst (La Frenais 2005: 9), and a physical performance by MIT's Xin Liu in 2017, in which Lui's wearable tethering device, the Orbit Weaver, was employed to impose a measure of control over uncontrollable drifting of the body in microgravity (Liu 2018). The film industry has also begun to recognise the potential for creative production in microgravity, and is beginning to understand how weightlessness may affect performance. Reduced gravity aircraft have provided the location for filming 
sequences in Apollo 13 (Howard, 1995), The Mummy (Kurtzman, 2017), and the music video for OK Go’s Upside Down \& Inside Out (Kulash and Sie, 2016). For Ron Howard, the location provided an opportunity to realistically replicate the physical conditions on board an Apollo spacecraft, for Alex Kurtzman, it replicated on out-of-control aircraft, tumbling towards the Earth, and for Damian Kulash and Trish Sie, the reduced gravity aircraft was a site for exploring the visual possibilities of objects and performers floating freely without gravity to constrain them. Alongside footage of astronauts on board the International Space Station, these three very different sequences provide insights into how clothing behaves in microgravity.

Costume designers must study these examples to understand the extent to which unconstrained fabric billows outwards, surrounding the body rather than draping from it, and how weightless bodies are encountered at a variety of different orientations, exposing parts of clothing that are not normally visible, and therefore not substantially considered during costume design or selection. Footage of actors and astronaut in weightless conditions demonstrates the extent to which clothing is one of the primary visible indicators of weightlessness, particularly in locations where many other objects are rigid or affixed to a surface, and are therefore less responsive to the effects of weightlessness. These insights are valuable for costume designers, who need to revisit some of their most fundamental assumptions about the behaviour of fabric and the body, as well as their approaches to design, which prioritize the upright, elevation view, and also for special effects artists, who seek to generate realistic simulations of weightless clothing. Costume designers, designing for real or simulated weightlessness, must closely study the effects of weightlessness not only for the sake of authenticity, but also because of the opportunities that commercial space travel presents for creative engagement with the effects of weightlessness on clothing and fabric.

\section{Case Studies: Apollo 13, The Mummy, and Upside Down \& Inside Out}

The first, and only use of a NASA reduced-gravity flight for the depiction of space travel took place for the filming of Ron Howard's Apollo 13 (1995). The film made extensive use of reduced-gravity flights for sequences throughout the film, interspersed with close-up shots filmed on Earth, with the result that the film was able to authentically replicate the effects of weightlessness on the actors, props, and costumes (Siede, 2015). Interviews with NASA crew 
recall how difficult it was to maintain control over props and cameras in this weightless environment, as the camera and its subjects would drift out of alignment (Bowden 1995: G01). Throughout the bulk of their journey, the actors are dressed in flight suits modelled on those worn by Apollo astronauts. With form-fitting suits such as these, which are cut tight against the body, there is little room for the garments to be deformed by weightlessness. As a result, it is difficult to differentiate the scenes in which the cast are genuinely weightless from those scenes shot on Earth's surface, and hence, easy for the filmmakers to maintain continuity. While we rarely see these suits deformed by weightlessness, the ways in which the clothed bodies respond to weightlessness is visible throughout sequences set on board the Apollo 13 spacecraft. Weightlessness is most visible in the presentation of elements of costume at angles that one would not normally encounter on Earth.

After launch, the first visible indication that the crew have become weightless is the behavior of their wearables (38.48-39.11). Jim Lovell (Tom Hanks) removes his helmet and releases it from his grasp. Rather than fall to the floor, the helmet remains aloft, and revolves slowly as it is suspended in mid-air in front of him. Jack Swigert (Kevin Bacon) and Fred Haise (Bill Paxton) then proceed to remove their own helmets and gloves. The released gloves and helmets float in all directions, crossing in front of the camera as they slowly revolve. Haise playfully spins his own helmet in front of him, excited by the novelty of its behavior. As these objects revolve in front of the camera, revealing every view, it is almost as if their design is the subject of a showcase, which intends to give audiences a detailed overview of the design by displaying them at all orientations. We see the fingers of the gloves, and then, as they revolve, the cuff, and then the wrist bearing. We see the palm, then the back of the fingers. We see the metal glimmer as the bearing catches the light, showcasing the design of its side, and then, the circular shape of the bearing framing the glove's dark interior as it revolves further.

Similarly, the flight suits are displayed throughout the film at a variety of uncommon angles. The actor's suits are frequently displayed in aerial view, with shoulder seams foremost. The screen is often dominated by an overhead view, as the astronauts are shown as if from above, so that the top of their head and shoulder seams face the camera, as the rest of the body recedes away from the camera $(48.34-48.48 ; 50: 40-50: 43 ; 51: 07-51: 10 ; 1: 22: 58-1: 23: 06$; 1:57:02-1:57:04). This is in part due to the cramped spaces on board the Apollo, which force the camera to be located overhead, and in part due to the way in which astronauts travel when 
weightless (that is, gliding through the cabin head-first, propelled by their hands that grasp and push-off from rails as they travel). On a number of other occasions, the screen is dominated by the seat of a pair of pants, as the camera follows crew from behind, and their bodies adopt a neutral body posture that resembles a relaxed seated position. At 47.43 we see the first of several scenes in which the camera pursues a body as it travels through the craft. Hauling himself through a narrow tunnel towards the lunar excursion module, Haise moves upwards relative to the camera, so that we see first a front view of his head and torso, then crotch, kneecaps, shins, soles, and finally, buttocks, as he bends his legs towards his chest and exposes his rear to the camera. He then inverses his body to face the camera, as if it is above his head, with the top of his shoulders visible in aerial view. Later an almost identical manoeuvre is performed by Swigert (1:06:55), who also exposes his rear and soles to the camera. The maneuver, and hence the view of the buttocks and soles, is not only the result of the need for the camera to pursue the actor through a narrow tunnel. It occurs again inside the main cabin, where there would be room for the camera to be located in front of the actor, were the actors' postures and positions not so affected by weightlessness (1:10:25-1:10:29). At no time are the actors shown in an upright, anatomical position, as weightlessness has relaxed their bodies into a neutral posture, with knees bent towards the chest. This visibly pulls the flight suits taught around their lower backs and seat, particularly at 48.08, when Haise gleefully performs a summersault with his arms clutching his legs against his chest. These are just some of numerous scenes in which the crotch or rear of the astronauts are dominant in the frame.

The effects of weightlessness on everyday clothes is recorded in Alex Kurtzman's The Mummy (2017). The film features a sequence in which an out-of-control aircraft plummets towards the Earth (32:00-33:36). Amid a desperate scramble to gather and don parachutes, the passengers become weightless as the plane enters freefall. The sequence depicts Nick Morton (Tom Cruise) and Jenny Halsey (Annabelle Wallis), grasping for parachutes as they float through the cabin. The scene was shot on board a Novespace reduced-gravity flight, in short clips filmed over sixty four parabolas, that were later pieced together to create a single scene (Lang 2017). The sequence illustrates how garments that are designed to drape downwards, hanging close to the wearer's skin, float away from the body in weightless conditions. Jenny wears a loose-fitting shirt and an unbuttoned gilet. As she floats through the cabin, the effects of weightlessness are seen as the hem of her gilet and shirt float away from her body, upwards and outwards, so that the garments take the shape of a flowing cape. 
Her vest is exposed as the hem of her gilet and shirt are lifted away from her back. Meanwhile, the jacket worn by Nick can be seen ballooning around his shoulders, creating additional volume and lifting the shoulder seams and collar in the direction of his head. As the passengers and crew float through the cabin of the aircraft, their bodies revolve and adopt a variety of orientations relative to the camera. The camera captures their clothed bodies at a variety of angles that would not normally be encountered.

A more prolonged 0G sequence can be seen in the music video for OK Go's Upside Down \& Inside Out. The video is constructed from a series of clips, filmed over the course of twenty one flights on an S7 reduced gravity aircraft (Howarth, 2016). It depicts the band members as passengers on a plane, along with crew in uniform, interacting with each other and their environment as weightlessness defamiliarizes their everyday actions and gestures. An array of colourful objects is released into the cabin, so that the space becomes steadily more chaotic as the video progresses. The band members, and two flight attendants, perform acrobatic maneuvers around the cabin, sometimes maintaining relative control over their location by holding onto hand rails, and at other times floating uncontrollably through the cabin. Meanwhile, their interactions with the weightless objects that surround them include popping piñatas, bursting balloons that had been filled with coloured liquid, and releasing coloured plastic balls from suitcases. Once released, these various props are shown floating through the cabin of the aircraft, colliding with each other, and with the passengers, and finally falling to the floor as Earth gravity is restored and the video ends.

The band members are dressed in colour-coordinated everyday clothing, including fully buttoned cardigans and shirts. As these clothes are relatively close fitting, they maintain their close proximity to the body throughout the video. There are moments, however, when the clothing bunches or lifts in ways that reveal that it is no longer suspended from the frame of the wearer. At 2:11-2:28 Damian Kulash, dressed in blue, flips his body upwards and rests horizontally, oriented parallel to the floor of the cabin, close to the ceiling, steadying himself on the hand rails, with his head closest to the camera and his feet further away so that we view his body as if from above. He then performs a number of flips before normal gravitational conditions return and he is lowered to the ground. During this maneuver it is possible to see how the uppermost part of Kulash's shirt and cardigan, at the collar and shoulders, is lifted away from his body so that it billows and adds additional volume around his shoulders. The same effect can be seen in footage of astronauts on board the International 
Space Station. Polo shirts, that one would otherwise expect to remain in contact with eth body and the shoulder seam and chest, instead balloon outwards, creating a pocket of air between the garment and the astronaut's body, so that the shirt, although surrounding the body, is not resting on it.

Throughout the video, the performers attempt to remain oriented vertically, relative to the camera, by grasping onto the handrails, seats, or other fixed parts of the aircraft's interior. Whenever they are not stabilized in this way, the performers' bodies revolve at various directions away from the camera. The bodies rarely share the same orientation, so that we may see the profile view of one performer while we see an aerial view of another. As they move from the front to the back of the cabin, or vice versa, they do so not by walking, but rather, by diving or floating with their bodies parallel to the floor. The overall affect is disorienting for both the performers and the viewers. The 360-degree view of each body that is revealed as they tumble through the interior space has the consequence of revealing every angle and surface of the performers' clothing, including the soles of their shoes.

While OK Go's video is groundbreaking in its production methods, and interesting to watch, it does not make as much use of the aesthetic potential of weightlessness as it could. The members of $\mathrm{OK}$ Go have chosen to evidence their weightless environment primarily through the movement of solid objects, including the band members themselves, which, and who, are set adrift in the cabin. The band members are dressed in relatively form-fitting clothes, and as a result the effects of weightlessness on their clothes are slight. Except in the moments described above, the effects of weightlessness on their clothing is barely noticeable. Indeed, in any single frame there is little visible evidence that the band members are not simply suspended from rigs in a studio on Earth's surface, imposed onto a digital environment and surrounded by computer-generated floating objects. Such evidence could have been provided by taking more substantial advantage of the untapped potential of the weightless environment, by, for example, selecting costumes that have been designed with weightlessness in mind.

\section{Lessons from Space}


As some spacesuit films have shown, the phenomenology of space travel can be affected as much by the wearing of a spacesuit as it is by the state of weightlessness. Immersion in a spacesuit makes the wearer hyperaware of his or her own physicality. Astronaut Chris Hadfield describes 'the gentle sound of the fan and the liquid cooling ventilation' that acts as a constant reminder that a spacesuit is working to sustain the flow of oxygen to the body. On a spacewalk, recalls Hadfield, the sound of 'your own breathing' is 'your [constant] companion' (Savage 2015). These sounds are characterized by their closeness, in contrast to the vast expanse of space, where the horizon is so incredibly distant that it curves around the entire circumference of a planet. Despite the vastness of this space-scape, every sound that the astronaut hears is generated from within or close to the astronaut's body. The vast and distant visual landscape bears no relation to the relatively minute and close aural landscape. Spacesuit films communicate the claustrophobia of the spacesuit, in contrast to the vastness of space, by enhancing or drawing attention to this aural landscape. In the opening sequence of Gravity (Cuarón, 2013), the camera passes from open space, through the visor of Ryan Stone (Sandra Bullock). As the camera enters the helmet, a soundscape of distant and 'muted sounds' of voices transported on radio waves is suddenly replaced by the loud, close, sound of her breathing (Bender 2014).

Films located on board spacecraft tend to be associated with space suits more than other aspects of astronauts' wardrobes. Cinema has paid little attention to the potential for more everyday items of clothing to play a role in signifying the physical and visual experiences of space travel, and in particular, weightlessness. The everyday clothing worn by space travelers inside spacecraft communicates the phenomenology of weightlessness in a number of noteworthy ways. Perhaps most notably, the sensations of weightlessness are indicated in the separation of clothes and body. Harriet Parry (2017: 99) tells us that 'cloth has a particular relationship with the human body. It is always in contact with, or imagined to be in contact with, the skin, our largest sense organ' (p. 89). In a weightless environment, however, clothed bodies are deprived of this sensation. The dialogue between garment, space, and body looks and feels very different. Clothing floats upward and outward, and away from the body. Astronauts become so accustomed to living without the weight of clothes against their skin that some report physical discomfort from contact with cloth after returning to Earth (Dunn 2016; Harrington 2016). Others who have experienced weightlessness describe a loss of awareness of where their body ends and where its surroundings begin. Without the sensation of pressure on the epidermis, skin 'stop[s] playing the role of sensor between the "interior" 
and the "exterior," between "me" and "what is not me" (Bureaud 2006). If the "external limits' of the body are unclear, then so too is the division between body and clothes.

Emphasis on the tactile qualities of clothes, resting upon or brushing against skin, contributes to an audience's sensorial immersion in a film. In her analysis of costume in Duncan Jones' Moon (2009) $)^{2}$, Harriet Parry (2017, p. 99) highlights the importance of costume in the production of haptic visuality, noting that 'the thingness of the cloth stimulates an awareness of the thingness of the body'. There is 'haptic and intuitive association between the skin of the subject [on screen] and our own skin' (Scholefield 2014: 44). In film that features a weightless environment, where skin comes out of contact with cloth, depiction of that loss of contact is a means by which to communicate the phenomenology of weightlessness. Writing in response to examples including 2010: The Year We Make Contact (Hyams, 1984) and Mission to Mars (De Palma, 2000), Adriano D'Aloia (2012) explores how 'intangibility is a constitutive element of representation, in particular in spacewalk scenes' or when a character on screen is suspended 'in the void'. D'Aloia takes a neurophenomenological approach that presents 'the very core processes of film "viewing" as an experience of tangibility.' From this standpoint, the depiction of tactile sensation is essential in creating for the viewer a sensorial experience. As the weightless environment is one in which a person is deprived of contact with its surroundings, and thereby deprived of tactile experience, there is a need to communicate to cinema audiences a 'tangible intangibility'. An on-screen character's apparent tack of tactile experience, such as lack of contact with a surface, plays an important role in communicating a sense of being weightless. In short, 'a state of suspense [in a void] is conveyed through... detachment from the ground', and, therefore, through detachment from surrounding objects, including costume.

One might argue, then, that form-fitting or skintight jumpsuits of the space age are inadequate as a means of conveying the wearer's weightlessness on screen. The authentic and sensorial depiction of weightlessness requires a depiction of the separation of clothes and body. This may mean a move away from the skintight catsuits of Barbarella or Space Age fashion, and the form-fitting jumpsuits that, while authentic in films such as Apollo 13 as depictions of NASA flight suits, are not effective at communicating the phenomenology of weightlessness. Skin-tight or form-fitting spacewear offer very little, if any, potential for visibly evidencing the sensation of weightlessness. They retain the same relationship with the body, regardless of the gravitational conditions. In conversation with the author, Susan 
Buckle (2017) of the UK Space Agency describes how operators of reduced-gravity flights recognize the limitations of regulation flight suits for passengers who wish to record visible evidence of their experience, and the extent to which passengers feel the need to compensate for the disappointment of wearing form-fitting clothes that are not made strange by weightlessness. Buckle recalls a flight during which her instructor encouraged her to 'let [her] hair loose,' recognizing that it would allow for more interesting photographs in which her weightlessness is visibly evident. Photographs of passengers with their hair flowing away from their heads in all directions provide evidence of the authenticity of their experience. Passengers and astronauts without long hair, or who are, for reasons of safety or practicality, strapped to their seats, employ objects on rigid cords or tethers to visibly evidence weightlessness. Like loose hair, these tethers float away from the body, almost as if they are underwater. ${ }^{3}$ Indeed, the aesthetic aspects of weightlessness that are most coveted by passengers appear to be more akin to those of underwater photography, in which hair and fabric billows outwards in ethereal swirls. A similar effect has been simulated in a number of films in which characters have found themselves, often lifelessly, floating through open space without a spacesuit, including Guardians of the Galaxy (Gunn, 2014) and The Black Hole (Nelson, 1979). Such images of the body, weightlessly suspended in a void, communicate the unsettling and unearthly sensation of being separated from all physical surroundings, including one's own hair and clothing.

Motivating Susan Buckle to let her to let her hair down in microgravity was a desire to create an unfamiliar silhouette; to transform the familiar shape of her own body into something strange. Part of the pleasure experienced by Buckle and other space travelers lies in the defamiliarization of familiar experiences, and the unexpected behaviours of familiar materials: Liquid pooling into undulating, floating spheres; a flame diffusing into a ball of fire instead if reaching upwards; 'the magic of things going where no mathematics or space architect's model has gone before' (Battaglia 2012: 1093). Cosmonaut Valentin Lebedev describes living in a near constant state of surprise and wonder throughout the first two months of his 211 days in orbit, as every familiar action and behaviour was defamiliarized by microgravity (Battaglia 2012: 1091-1093). Defamiliarization is at the heart of speculative design for space tourism, pre-empting an anticipated future demand for commercial space travel that incorporates uncanny representations of everyday Earth experiences. When James Parr was employed by distiller Ballentine to redesign a whisky glass for space, he began by inverting the relationship between drink and glass. Parr's solution was not to attempt to 
'control where the liquid goes' but rather to control 'the vessel around the liquid' (Ballantine 2015). An important lesson to be learnt from such examples is that some modification or reinvention of everyday artefacts, such as clothes, is required for the related everyday experiences to be defamiliarized in pleasurable or interesting ways.

Footage of astronauts on board the ISS, made publicly available by NASA, goes some way towards demonstrating the effects of weightlessness on everyday clothing, and on the relationship between clothes and the body. While not clothed in space suits or branded flight suits, astronauts are permitted to wear commercially available, off-the-shelf (COTS) 'routine wear' (NASA 2015: 194). Routine wear typically includes polo shirts, sweatshirts, and cargo pants or shorts, selected from approved commercial vendors. Although it is acknowledged that 'custom clothing would better meet requirements,' the development of specialist garments for everyday wear on board the ISS 'would drive up costs and limit availability' (Fratto 2005: 18). Hence, NASA astronauts spend much of their time in space wearing garments that were not originally intended to be worn as spacewear. The problems arising from NASA's use of commercial off-the-shelf clothing tell us that there are numerous disadvantages to the wearing of Earthwear (clothes that were intended for Earth gravity) in a weightless environment. The routine wear fits its wearers more awkwardly than it does in Earth's surface (see figure 1). Off-the-shelf clothing, or more broadly, clothing that has been designed as Earthwear, is distorted by weightlessness in ways that cause an overall effect described by Annalisa Dominoni (2005: 4) as 'slovenliness'. Dominoni observes 'crew members with t-shirt collars rucked up around their necks' as weightlessness lifts the collar and shoulder seams upwards relative to the astronauts' heads. Meanwhile, astronauts' 'backs [are] uncovered because garments have not been designed to consider body postures, movements and physiological alterations caused by microgravity.' As in The Mummy's air crash sequence, astronauts' shirts drift upwards and billow outwards, as is floating around the body but not adhering to its contours.

Figure 1: Astronaut Sandra Magnus, Expedition 18 flight engineer, floats between two Russian Orlan spacesuits with Santa hats in the Harmony node of the International Space Station. The effects of weightlessness are visible in the shape of Magnus' sweatshirt, which billows outwards from her body, surrounding it but not resting on it. The sweatshirt is only in contact with her body where it is held in place by her tight waistband. By contrast, her 
trousers show few visible indicators of weightlessness, as their tight-fitting form does not allow for distortion. NASA ISSO18-E-014692. (C) NASA, 2008.

Further lessons can be learned from Japanese designer Eri Matsui, whose speculative design for a Zero Gravity Wedding Dress accommodates the potential for fabric to billow away from the body (Finnegan 2016). Matsui's dress is a compromise between freedom and constraint, working both with and against the weightless conditions for which it was designed. It features waterfall ruffles, running vertically from shoulder to waist, and below the waistline, columns of draped silk that resemble a floor-length skirt. This surface layer makes the most of microgravity's ability to lift draped cloth, with ruffles that drift and undulate while weightless. Beneath is a more functional layer of separate bodice and trousers, designed with functionality in mind. Matsui has recognized that to preserve the modesty of the wearer, and to maintain an approximately skirt-like silhouette, one must begin with a trouser-like foundation. In the weightlessness of a zero-g flight, the form-fitting lower layer of Matsui's dress secures the garment in place, ensuring that the body remains reliably concealed while only the outer layer floats free.

These various observations suggest that when designing costume for the weightless environment we must consider, as Harriet Parry argues, the extent to which the relationship between clothes and the body contributes to the haptic visuality of a film; We must consider, as reported by Susan Buckle, the ways in which passengers of reduced-gravity aircraft express desire for weightlessness to be visibly evidenced and defamiliarized by loose or freeflowing materials; We must also consider the extent to which, as Annalisa Dominoni observes, some off-the-shelf Earthwear is awkward and visually unappealing when distorted by weightlessness. Weightlessness is a physical rather than visual spectacle, but can be made visual through the use of visible objects that are selected or designed to visibly respond to weightlessness. If cinema and television seek to emphasize the effects of weightlessness on clothing, they must begin to move away from defaulting to skin-tight or form-fitting flight suits, and begin to also depict costumes that have been designed to visibly evidence the effects of weightlessness. Those materials that are most visibly affected by weightlessness are those that do not have a fixed form. While solid forms with a stable shape merely appear to float in mid-air, objects with a fluid or malleable form have the potential to distort into strange, otherworldly shapes. Unstiffened fabrics, and by extension, clothes, have this potential. An unstiffened and unconstrained garment will extend away from the body in ways 
that celebrate the visible effects of weightlessness, through changes in silhouette and the separation of garment from body.

\section{Approaches to Costume Design for the Weightless Environment}

In order to develop any designed object for the weightless environment, we must recognize, argues Eduardo Kac (2005: 18), the extent to which gravity informs the design of objects that we create on Earth, so that we can understand how objects intended for zero-g must be 'radically different'. The long history of design has taken place within Earth's atmosphere. Designers take for granted numerous fundamental principles, such as the upright orientation of objects, the stabilizing effects of the weight or density of materials, or of a flat base. In dressmaking and fashion design, designers begin with numerous assumptions that are dependent on Earth's gravitational conditions, concerning themselves with the weight and drape of fabric, and designing garments primarily to be viewed in an upright arrangement. To design for the weightless environment, many of these fundamental ideas need to be revisited or discarded completely.

Observations of footage filmed on board space stations and reduced-gravity aircraft show us that there are three fundamental aspects that must be considered when designing costume for the weightless environment: orientation, posture, and drape. Vertical orientation, is very much taken for granted in established design practice. From the moment of conception, designs tend to be depicted and displayed upright, showing front, side, or rear views. The tendency to primarily display elevation views has led to notions that the silhouette is one of the defining characteristics of a garment, to the extent that key developments in fashion history have been described in terms of changes to the silhouette. As a result, Earth-based designers tend to think little about alternative views of a garment, such as the aerial view.

When a clothed body approaches a camera in a weightless environment, it is likely that the actor's body will not be presented in elevation view. Rather, they will drift towards the camera at an angle that will expose their costume at alternative orientations, or revolve to reveal their costume at many different orientations. As in the microgravity sequences of Apollo 13, the elevation view of a costume - the silhouette - is never seen. The footage of actors' passage through the cabin of the Apollo spacecraft shows actors propelling 
themselves through the cabin with their hands. Rather than striding past the audience as would a model on a catwalk, revealing a garment from front to back as the model parades and then turns, these weightless actors glide above the camera so that their costumes are revealed gradually from shoulder to toe as they pass. Videos recorded on board the ISS show astronauts and cosmonauts struggling to maintain their orientation, upright relative to the camera, for the duration of their live broadcasts to Mission Control. Similar scenes are seen in the OK Go case study above, with band members' bodies exposed to the camera from all angles, exposing the tops of their heads, the soles of their shoes, and every other view of their costumes. When designing costume for the weightless environment, therefore, notions of 'top' and 'bottom' will need to be discarded, as 'up' and 'down' hold no meaning in microgravity (Wood 2014: 443; Fisher 2009: 66). While we rarely view a garment from above or below on Earth, microgravity conditions will expose these unseen surfaces, forcing designers to consider the appearance of a garment not just from the front, back, and sides, but also from above, below, and all other angles in between.

This likelihood that a costume will be depicted from uncommon angles means that there is a need to consider and enhance the unseen shapes of a garment, such as the circular hem of a skirt when viewed from below, or the colour of lining that might be viewed on the underside of that same skirt. Earthbound filmmakers have made good use of aerial, overhead, and highangle shots. However, when an actor is stationary and rooted to the ground, these shots tend to provide a neat view of only one aspect of a costume, such as the aerial silhouette. By contrast, neutral body posture, as can be seen in so many shots in Apollo 13, combined with the suspension of the body at unconventional angles, as in OK Go's music video, leads different parts of the body to present themselves at different angles simultaneously. A shoulder, as if viewed from a high angle, might appear in frame at the same time as the kneecaps, bent upwards towards the chest; the soles of the feet may dominate the frame against a backdrop of crotch and torso. When designing for a microgravity shoot, costume designers will need to abandon their preconceptions about the primacy of the front or side silhouette and instead begin to consider the appearance of a garment from all orientations, or indeed, aspects of multiple orientations simultaneously.

Neutral body posture must be considered not only because it contributes to the angles at which different parts of a costume are presented, but also because of the way in which posture affects fit. The clothed body on display in upright orientation tends, on Earth's 
surface, to be standing or seated. Clothes are currently, with few exceptions, designed for an upright pose known as the 'anatomical position,' with spine erect, legs straight, and feet flat on the floor (Watkins and Dunne 2015: 36). This is the pose of the dressmaker's dummy, but very different from the pose of a human body in a weightless environment. The weightless body relaxes into a posture that is not unlike that of a snowboarder, with head forward, and limbs slightly bent, as if partway between standing and seating (Dominoni 2003: 278). One consequence of the neutral posture is ill-fitting garments. Dressmakers who work with dummies in the anatomical position may be ill-equipped to imagine solutions to the problems that arise when clothing the body in neutral posture.

Observing the fit of garments on a body with neutral posture, as in NASA footage from the ISS, it is possible to identity points of poor-fit where the fabric is stretched uncomfortably tight, falls untidily loose, or fails to adequately cover the body. Particular points of concern for dressmakers and designers are the collar, armscye, elbow, waist, seat, crotch, and knee. The neutral posture requires garments that are longer in the back; shorter in the front; looser around the knees, seat, and shoulders; and with neckhole and waistband positioned further forward than on garments designed for Earth gravity. At the waist, there is potential for gape at the back and unwanted pressure at the front. The hemlines of shirts lift at the back, and rear of the waistbands of trousers and shorts gape or are pulled downward, leaving an area of the lower back exposed (much like the exposure of Annabelle Wallis' back during the zero-gravity sequence in The Mummy). Meanwhile, the front of a waistband can become gathered and tight, applying uncomfortable pressure to the abdomen. A longer seat seam at the rear, and shorter rise at the front, helps position the waistband on a horizontal line. Much can be learnt from tailors who accommodate a stooping posture, with a forward bend of the spine, or who have addressed the needs of wheelchair users, whose clothes are designed for the seated position (Nowack 2001: 878).

Finally, and perhaps most importantly, costume designers must consider the way in which fabric behaves while weightless, in contrast to the ways in which it drapes in Earth gravity. Of the numerous texts that explore and define drape, many explicitly or implicitly associate it with gravity: Yan, Cui, and Hu (2012: 661) describe how, 'under the action of gravity[...] fabrics will droop[...] and form curved surfaces'; Cadigan (2014: 140) categorizes all fabrics according to the extent to which they 'resist gravity'. On Earth, weight is closely associated with drape. The weight of a fabric dictates the way that a fabric will distort when draped over 
the body (Zaihuan Mei et al. 2015: 1; Hunter and Fan 2008: 7). When a garment is weightless, this rule no longer applies. As D’Aloia (2012) rightly acknowledges, when gravity is suspended, tactility is also suspended, and the subject loses contact with their surroundings. Earthbound dressmakers must discard the assumption that a garment will hang on a human figure, or come into regular contact with the body, typically at the shoulder seams, bust, hips or waistband. In a weightless environment, gravity does not hold the garment in contact with the body at those locations; rather, the garment floats around the body. As a result, fabric does not drape, but rather billows outward. Length, which we commonly define as a vertical measurement, can be transformed into a radial measurement, as loose fabric floats outwards, away from the body. In order to create an impression of the sensation of weightlessness, therefore, it is important to show the separation of cloth and skin. When cloth rests against our skin we are reminded not only of the presence of our clothes, but also the presence of gravity; and in order to communicate the loss of gravity, we must show that cloth has come out of contact with the skin. Costumes should be designed to billow away from the body. The more extreme this effect is, the more potential there is for visual spectacle, defamiliarizing the garment, and making strange the relationship between clothes and the body.

For a costume designer, the perceived loss of gravity might lead to a perceived loss of control. Without the ability to control a silhouette as the fabric of a garment billows outwards in unpredictable ways, costume designers may need to counteract the effects of weightlessness. The relationship between drape and structure is thrown out of balance, sometimes with unwanted consequences, such as unwanted exposure of some body parts, or the unwanted concealment of others. However, in this unfamiliar environment, designers can seek new relationships that provide new ways of controlling the shape of a garment. A fashion designer's goal, argues Cadigan (2014: 125), should be to pursue a 'balance between drape and structure'. This relationship continues to exist in weightless environments, but it takes a new form. As on Earth, stiffening of fabric can be one way to control aspects of shape. Similarly, the relationship between support and drape does not fully disappear, rather, it may need to be reframed as a relationship between freedom and constraint. The extent to which weightless fabric billows away from the body can be controlled by forcing points of contact with the body, either through close-fitting form, or with elasticity. 


\section{Conclusion}

The commercial space industry offers new opportunities for the creative industries, and increases audience expectations about the authenticity of depictions of weightlessness. The film and television industries have only just begun to exploit opportunities to film on board reduced-gravity aircraft for authentic depictions of weightless environments. As weightless environments become more accessible, there will be an increasing appetite for authentic depictions of microgravity. Where authenticity is required, filmmakers must consider not just the provision of authentic sets, costumes, and props, but also the authenticity of the ways in which these objects behave in the environment. Due to its fluidity and relationship with the body, costume has the potential to act as an indicator of authenticity in depictions of weightlessness. In order to evidence this authenticity, props and costumes need to be designed in ways that visibly respond to weightlessness. In other cases, where the filmmaker's intention is not authenticity but surrealism, the weightless environment may be chosen because of its capacity to create an ethereal, otherworldly effect. Here, there is a need for props and costumes to be designed so that they are made strange by weightlessness. There is therefore, regardless of whether the goal is for footage to feel more real or more strange, a need for filmmakers to select or design props and costumes that behave differently in 0G to how they behave in $1 \mathrm{G}^{4}$

For costume designers, it is important to acknowledge the importance of the relationship between clothes and the body, and the part that this plays in the sensory experience of a film. In $0 \mathrm{G}$, the relationship between clothes and the body is unfamiliar and spectacular, and this appealing strangeness can be exploited by filmmakers and costume designers if they are prepared to discard many of the fundamental assumptions about the behaviours of fabric and the human body. When designing costume for weightless environments, the behavior of fabric is disconnected from qualities (such as weight) that play such an important role in the design of Earthwear, and new, different behaviours occur. Garments need to be designed with these new behaviours in mind. Designers must set aside expectations about weight and drape, and find a new balance between fluidity and structure. Further, designers must be conscious of the appearance of a garment from all angles, considering not only the elevation views (front, back, side), but also aerial views and all other orientations. Only if filmmakers take the 
effects of weightlessness on costumes into account will they be able to fully exploit the opportunities provided by the new commercial space age.

\section{References}

Ballantine ( 2015a ), 'How Do You Make a Whisky Glass for Space?' Medium, 2 September, https://medium.com/space-glass/how-do-you-make-a-whisky-glass-for-space33d83797ad82\#.5436jx30x. Accessed 6 July 62016.

Battaglia, Debbora (2012), 'Coming in at an Unusual Angle: Exo-Surprise and the Fieldworking Cosmonaut', Anthropological Quarterly, 85:4, pp. 1089-1106.

Bender, Stuart (2014), “"There is Nothing to Carry Sound”: Defamiliarisation and Reported Realism in Gravity', Senses of Cinema, 71. http://sensesofcinema.com/2014/featurearticles/there-is-nothing-to-carry-sound-defamiliarization-and-reported-realism-in-gravity/ . Accessed 12 July 2019.

Bowden, Mark (1995), 'Zero Gravity: Take One', The Philadelphia Inquirer, 24 July, p. G01.

Buckle, Susan (2017), telephone interview, 5 May.

Bureaud, Annick (2006), '”What if . ..” Art and Weightlessness', in M. Bakke (ed.), Going Aerial: Air, Art, Architecture, Maastricht, Netherlands: Jan van Eyck Academie.

Cadigan, Erin (2014), Sourcing and Selecting Textiles for Fashion, London: Bloomsbury Cuarón, Alfonso (2013), Gravity, USA/UK: Warner Brothers.

D’Aloia, Adriano (2012), 'The Intangible Ground: A Neurophenomenology of the Film Experience', European Journal of Media Studies, 1:2, pp. 219-239 .

De Palma, Brian (2000), Mission To Mars, USA: Touchstone Pictures.

Dominoni, Annalisa (2005), 'Aesthetics in Microgravity', in J. E. Katz (ed.) Machines That Become Us: The Social Context of Personal Communication Technology, New Brunswick, NJ: Transaction, pp. 277-284.

Dominoni, Annalisa (2005), 'VEST. Clothing Support System On-Orbit Validation', SAE Technical Paper presented at the 25th International Conference on Environmental Systems (ICES), Rome, Italy: 11-14 July, http://hdl.handle.net/11311/255047. Accessed 25 July 2015. 
Doule, Ondřej (2014), 'Ground Control: Space Architecture as Defined by Variable Gravity,' Architectural Design, 84:6, pp. 90-95 .

Dunn, Marcia (2016), 'A Year in Space: Aching Joints and the Weird Feeling of Clothing Touching Your Skin', Global News, 4 March, https://globalnews.ca/news/2558552/ayear-inspace-aching-joints-and-the-weird-feeling-of-clothing-touching-your-skin/ . Accessed 27 January 2018.

Extant (2014-2015), USA: 22 Plates, Amblin Television, CBS Television Studios.

Finnegan, Erin (2016), telephone interview, 17 March.

Fisher, Adam (2009), "'Very Stunning and Very Cool”: The Launch of Space Tourism', Technology Review, Jan/Feb, pp. 58-69 .

Fratto, Lisa (2005), 'Evaluating the Performance of Fibres and Fabrics for Astronaut's IVA Wardrobes for Long Duration Space Flight', MS dissertation, North Carolina State University. http://repository.lib.ncsu.edu/ir/bitstream/1840.16/2074/1/etd.pdf. Accessed 10 August 2015.

Gast, Mathew A., and Sandra K. Moore (2011), 'A Glimpse from the Inside of a Space Suit: What Is It Really like to Train for an EVA?', Acta Astronautica, 68:1-2, pp. 316-325.

Grzinic, Marina (2003), 'Aesthetics of the Digitized Body', in K. Nishimura (ed.), Selected Papers of the 15th International Congress of Aesthetics, Tokyo: Organizing Committee of the 15th International Congress of Aesthetics, pp. 81-86 .

Gunn, James (2014), Guardians of the Galaxy, USA: Marvel Studios.

Harrington, Rebecca ( 2016), 'A Famous Astronaut Says His Body Still Hurts after Spending a Year in Space', Business Insider, 8 June. http://uk.businessinsider.com/scott-kellyspacetravel-effects-human-body-2016-6?r=US\&IR=T. Accessed 15 December 2017. Hood, Gavin (2013), Ender's Game, USA: Summit Entertainment.

Howard, Ron (1995), Apollo 13, USA: Universal Studios Home Entertainment.

Howarth, Dan (2016), 'OK Go performs in zero-gravity for Upside Down \& Inside Out music video', Dezeen, 10 February. https://www.dezeen.com/2016/02/20/ok-go-performs-inzero-gravity-for-upside-down-inside-out-music-video-interview-trish-sie/. Accessed 22 July 2019. 
Hunter, L., and Fan, J. (2008), 'Measuring and Predicting Fabric and Garment Drape', in C. Fairhurst (ed.), Advances in Apparel Production, Cambridge, UK: Woodhead, pp. 7-25 . Hyams, Peter (1984), 2010: The Year We Make Contact, USA: Metro-Goldwyn-Mayer. Jones, Duncan (2009), Moon, USA/UK: Sony Pictures.

Kac , Eduardo ( 2005), 'Against Gravitropism: Art and the Joys of Levitation', in N. Triscott and R. La Frenais (eds), Zero Gravity: A Cultural User's Guide, London: Arts Catalyst, pp. $18-25$

Kulash, Damian and Sie, Trish (2016), Upside Down \& Inside Out, music video for OK Go. Kurtzman, Alex (2017), The Mummy, USA: Universal Pictures.

La Frenais, Rob (2005), 'An Introduction to Vertigo', in Zero Gravity: A Cultural Users Guide, London: The Arts Catalyst.

Lang, Brent (2017), 'Tom Cruise's Zero-Gravity Stunt in “The Mummy” Took 64 Takes', Variety, 29 March. https://variety.com/2017/film/box-office/mummy-tom-cruise-zerogravity-stunt-1202018681/. Accessed 9 July 2019.

Liu, Xin (2018,) 'Project Overview: Orbit Weaver', MIT Media Lab, 16 July, https://www.media.mit.edu/projects/orbit-weaver/overview/. Accessed 2 May 2019.

Lundén, Elizabeth Castaldo (2016), 'Barbarella's Wardrobe: Exploring Jacques Fonteray's Intergalactic Runway', Film, Fashion \& Consumption, 5:2, pp. 185.

Muschietti, Andy (2017), It, USA: New Line Cinema.

NASA (2015), 'NASA Space Flight Human-System Standard, Volume 2: Human Factors, Habitability, and Environmental Health (Revision A)', NASA Technical Standard, https://standards.nasa.gov/standard/nasa/nasa-std-3001-vol-2. Accessed 22 July 2019.

Nelson, Gary (1979), The Black Hole, USA: Walt Disney Productions.

Nolan, Christopher (2010), Inception, USA/UK: Warner Brothers.

Nolan, Christopher (2014), Interstellar, USA: Paramount Pictures.

Nowack, E. ( 2001), ‘Anthropometry for Design', in W. Karwowski (ed.), The Encyclopedia of Ergonomics and Human Factors, Volume II, New York: Taylor and Francis, pp. 875-878 . Parry, Harriet (2017), 'Moon: A sensuous scholarship of the art of costume breakdown in film', Film, Fashion \& Consumption, 6:2, pp. 89-103. 
Peeters, Walter (2010), 'From Suborbital Space Tourism to Commercial Personal Spaceflight', Acta Astronautica, 66:11-12, pp. 1625-1632 .

Savage, Adam (2015), ‘Adam Savage Incognito at Comic-Con 2015 (with Astronaut Chris Hadfield)', Tested. http://www.tested.com/art/. Accessed 23 July 2019.

Scholefield, Joanna (2014), 'Under the Skin: How Filmmakers Affectively Reduce the Space Between the Film and the Viewer,' Film Matters, 5:1, pp. 44-53.

Siede, Caroline (2015), 'On Apollo 13's 20th anniversary, a look at how they made the film so realistic', $A V$ News, 30 June, https://news.avclub.com/on-apollo-13-s-20th-anniversary-alook-at-how-they-mad-1798281369. Accessed 16 July 2019.

The First (2018), USA: Westward Productions, AG Capital, AG Studios, Channel 4 Television Corporation, Hulu, IMG.

Thorpe, Andrew M. (2009), The Commercial Space Station: Methods and Markets, Bloomington, IN: Authorhouse.

Tyldum, Morten (2016), Passengers, USA/Australia: Columbia Pictures.

Universal Pictures (2017), 'The Mummy - Zero Gravity Stunt in 360', YouTube, 16 June 2017, https://www.youtube.com/watch?v=gUMT4scl8dU. Accessed 3 May 2019.

Vadim, Roger (1968), Barbarella, Italy, France and USA: Dino De Laurentiis

Cinematografica/ Marianne Productions/ Paramount Pictures.

Watkins, Susan M. and Dunne, Lucy E. (2015), Functional Clothing Design, London: Bloomsbury.

Westfahl, Gary (2012), The Spacesuit Film: A History, 1918-1969, London: McFarland. Wood, Aylish (2014), 'Gravity by Alfonso Cuaron (Review)', Science Fiction Film and Television, 7:3, pp. 441-444.

Yan, Jiang, Cui, Minghai and Hu, Jing (2012), 'Computer Generation of 3D Textile Draping Simulation', in D. Wei (ed.), Proceedings of the AASRI Conference on Modeling,

Identification and Control, Hong Kong, 19-20 December, pp. 661-666.

Zaihuan Mei, Wei Shen, Wang, Yan, Yang, Jingzhi, Zhou, Ting, and Zhou, Hua (2015), 'Unidirectional Fabric Drape Testing Method', PLoS ONE, 11:10, pp. 1-15 . 


\footnotetext{
${ }^{1}$ This is aptly demonstrated in the styling of Sean Penn's hair, gelled upwards and outwards so that its stands on end, as astronaut Tom Hagerty becomes one of the first men to journey to Mars in Hulu's The First (season 1, episode 8, "Near and Far"). The difficulty of simulating weightless hair perhaps explains why so many films set on board spacecraft choose to feature astronauts with cropped hair, or hair held tightly back.

${ }^{2}$ It worth noting that Moon depicts its protagonist and his costume in apparently familiar gravitational conditions, being set on the surface of the Moon (1/3 Earth gravity), rather than on board a spacecraft. Therefore, the costumes remain draped on the body.

${ }^{3}$ NASA recognises the similarities between the underwater environment and microgravity, and trains astronauts to conduct microgravity procedures underwater in Neutral Buoyancy Labs. They recognise, however, that this is an imperfect simulation (Gast and Moore, 2011, p. 318).

${ }^{4}$ It is worth noting that a range of gravitational conditions, not just $0 \mathrm{G}$ or $1 \mathrm{G}$, can be experienced during space travel and reduced gravity flights. Ondřej Doule (2014: 90), editor of the short-lived space architecture magazine The Orbit, describes design for space as 'defined by variable gravity'. It is important to acknowledge that many future spaceflight participants will experience only short-term weightlessness, and that various other gravitational conditions may also need to be depicted on film.
} 